\title{
The Translator's Position in the Screen Translation from the Angle of Translation Ethics
}

\author{
Changhong Zhai ${ }^{1,}$ a , Wanfang Zhang ${ }^{2}$, ${ }^{*}$ \\ ${ }^{1}$ School of Foreign Languages, Wuhan Polytechnic University, Wuhan, China \\ ${ }^{2}$ School of Foreign Languages, Wuhan Polytechnic University, Wuhan, China \\ aemail: 594561792@qq.com, bemail:420300466@qq.com \\ ${ }^{*}$ Corresponding author
}

Keywords: Designtranslator's Position; Screen Translation; Translation Ethics

\begin{abstract}
As a special branch of literature translation, screen translation naturally obeys the basic rules of literature translation and has its features as well. During translation, the principle of "Faithfulness, Expressiveness and Elegance" in literature translation fails to explain some specific problems in screen translation. Translation is not only a linguistic phenomenon, but also an ethic problem. This paper tries to focus on the translator's position in screen translation from the angle of translation ethics.
\end{abstract}

\section{Introduction}

With China's entry in World Trade Organization and the globalization, we are getting closer with the world. Movie, a western fashion product, once has been regarded as a monster by Chinese people and now is playing an important role in people's entertainment. Movie and television make us learn more about outside world by broadening our visions and enriching our leisure life. The quality of the screen translation directly influences the arts display and commercial attraction of a movie, which closely relate to the box office returns so that the screen translation is of great significance in propagation of a movie. If the foreign information is presented without processing, it will be hard and complex for the community to understand. As the communication among countries continue to enhance, the qualification of screen translation become more and more important. The qualities of foreign movie translation works by Chinese people, temporary, are uneven due to the lack of management. This phenomenon seriously damages the position of the translator among the audience, at the same time, affects enjoyment of the movie. Consequently, the screen translation is so important that cannot be ignored. This essay is going to discussing the translator's position in screen translation from the prospect of translation ethics.

\section{Several Problems in Translation Ethics Studies}

Definition of Translation Ethics. In the 1980s, Antoine Berman, a French translation theorist, proposed the concept of "translation ethics". From then on, western translation studies returned to translation ethics.Ethics, also known as moral philosophy, is a branch of philosophy that addresses questions about morality — that is, concepts such as good and evil, right and wrong, virtue and vice, justice and etc. The core of ethics is morality. Generally speaking, they all concerned about people's behavioral norms. In English, the word "ethics" is connected to value judgment and often refers to certain professional regulations or norms that are obeyed by practitioner.

Translator's Morality and Utilitarianism. The ethic issue, in fact, is about making the choice between the morality and utilitarianism. Theoretically, a translator is obliged to translate faithfully. Actually, ethic values are directly connected with people's being. Throughout the history of western and Chinese translation theories, enormous translators undertake the social duty and obligation to translate. For this reason, to judge whether a translation's behavior is moral or not, it depends on the utility on readers' ethics or morality, not depends on the utility on the whole society.

However, a translator lives in a society, and he connects with people. A translator is not a tool or 
a machine, but a lively human being with his/her own emotion, moral character, utility and his/her own pursuit. As a result, we must admit the existing of utilitarianism and selfishness is reasonable. If it cannot satisfy the human beings by meeting their interest, no matter how sublime or perfect an "ethic concept" or an "ethic requirement" is, it will remain an illusion which is never practical or functional in reality.

Universality and Particularity of Translation Ethic Norms. From the prospect of ethics, translation norms can be divided into personal norms and social norms, namely common norms and special norms. The common norms that can apply to any human society, any historical period should be abided by any translators. No text is allowed to infringe the common rules. It is the ultimate goal that translators seek for, which means the commitment to excellence of translation. On the contrary, the special norms are only propitious for given texts, given service objects for given periods. Some translators are asked to comply with these norms, while some are not. As the soul of translation, a translator needs to discover and settle down the common norms of source language in accordance with the cultures and conventions of the target language. In addition, he/she must pay attention to the relationship between the rights and interests in source language, and special norms settled for translation. Every translating strategy a translator chose should satisfy both the universal norms and the personal ethics.

\section{Professional and Personal Ethics of Translator}

Professional Ethics of Translator. Professional ethics concerns the moral issues that arise because of the specialist knowledge that professionals attain, and how the use of this knowledge should be governed when providing a service to the public. If a person wants to be acknowledged by the profession, he/she needs to accept all the common professional codes. Ethics means the pursuit of the most excellent translating products and the loyalty to the translating job. In particular, professional ethics of translators is supposed to meet the social expectancy. Being a member of translation industry, a translator will never abandon his/her efforts to become outstanding. Except for having a good command of source language and thoroughly understanding of original texts, a translator should have some other fine qualities.

Personal Ethics of Translator. In reality, there exists something more important than professional ethics, which are out of the control of professional ethics. For example, the political background of a translator can make an impact on the way he/she translates. An anti-fascist translator will modify a fascist text he/she translate, which means that he/she put personal ethics before the professional ethics. Lawrence Venuti, an American translation theorist, once said, " No matter where a translating conduct is taking place, no matter what forms a translating job is done, it is always under the restriction of certain environment." Each society insists that its codes are moral. Living in a society, neither the translator nor the author can escape from their own social traditions. These ethic traditions have a great influence on their personal ethic faith. A mediator as a translator is, he/she is interfered by the ethic systems of source language and target language.

Contradiction Between the Professional and Personal Ethics. Every translator is not willingly to either betray the professional ethics, or put his/her personal ethics to great inconvenience. Nevertheless, the realistic picture is that there is a contradiction between the professional ethics and personal ethics for often times. The professional ethics can prevent translators from being excessively subjective, and then the translators will be more objective and impartial. In opposite, the long-standing social ethic systems in both source language and target language hinder the translators obeying their own professional codes. With the growing attentions attached to the factors influencing the translators, it is urgent to settle down the contradictions between professional codes and personal ethics.

Translator's Norms of Honor and Shame. A translator with a strong sense of ethics will never 
ever go over domesticating the original text. Nor will he/she foreignize. He/She stands at the middle ground of the cultures. A translator is a merciful and equitable Saviour, a promoter in enhancing cultural exchange towards healthy and democracy. A translator with a strong sense of ethics is responsible for both source language and target language. He/She cannot make any decisions with his/her own emotion and thought. His/ Her personal ethic inclination cannot take sides with a certain culture. Under any circumstances, a translator should not replace the professional ethics by the personal ethics.

\section{Translator's Position in Screen Translation}

Screen Translation. Screen translation belongs to a special branch of literature translation, in other words a special literature translation. Naturally it has to follow the basic principles of literature translation: (1) a translation should give a complete transcript of the ideas of the original words; (2) the style and manner of writing (in a translation) should be of the same character as that of the original; and (3) a translation should have all the ease of original composition. The translator usually faces with a variety of translation strategies to choose from. For one thing, movies and television programs bear distinct literature attribute. For another, as a plug generation of arts and literature, screen literature has some new attributes that traditional literature forms have not.

Specialties of Screen Translation. On account of cultural differences between western countries and China, screen translation cannot avoid the impact of cross-culture communication. Consisting of a major part of mass media, screen translation has linguistic specialties like anglicizing, lip synching and characterizing, emotionizing and popularizing. Here are some examples of translations of movies: Firstly, screen translation plays an important role in crossculture communication with its irreplaceable specialties. In 1980s, the course of screen translation is China is taking off. People learned knowledge about foreign economy and culture. Secondly, the translator needs to notice some special principles for translation and comply with special theories. Traditional methods of translation are word-for-word translation, adaptation, sense-for-sense translation, faithful translation, idiomatic translation, domesticating and foreiginizing and so on. There are some contradictions between word-for-word and sense-for-sense due to the divergences of linguistic contexts and forms. At last, some factors like the cross-culture communication, cultural background and social convention are the key ingredients of screen translation. As the result of huge differences among the domestic and foreign audience, screen translators aim at helping audiences understand the linguistic phenomena closely related to history, geography and regions.

Subjectivity of Translator. Zha Mingjian holds the opinion that under the premise that the translator respects the original text; the subjectivity of translators refers to the subjective initiative expressed by the translators while realizing the goal of translating activities. The basic features are being culturally self-conscience and aesthetically creating. In general, the essence of subjectivity lies in the initiatives, restrictive and selfishness.

Creativity of Translator in Screen Translation. Language and culture are inseparable. And languages of different countries reflect their cultural shocks. Then, how to deal with these differences? There exist a debate on domestication and foreignization. It is hard to decide which method is better. It is determined by two elements: the readers of the translated text and the goal of translating. Because of these, when translators are handling cultural differences in screen translation, they should have the audiences and purposes of the movies and televisions in mind. Nevertheless, to arrive at the purpose of entertainment, screen translation is requested to catch up with the plot as well as keep the beauties of the original movies remain. According to these, there are three principles for dealing with cultural difference: (1) translated language must be easy-to-understand; (2) keep the story go on smoothly; (3) remain the original aesthetic appreciation. It seems that domesticating can meet all these requirements. Creativity is the designed feature of literature translation, which determined by the object. The movies and televisions are different from literature 
works for that they are multi-media arts combining audio and vision. Their multiplies give the translators larger space for creating than literature. However, it does not mean a free and vigorous style of translating. It has restricts: (1) the pictures are conducive to creation of translators; (2) the limitation of the pictures forces the translators to create; (3) the transient dialogues ask the translators to be creative.

\section{Conclusion}

A translator's job is to change a language or a system into another language or another system. Under the background of translation studies returning to translation ethics, it is highly significant to study screen translation from the angle of translation ethics. Professional translation ethics is crucial for every scholar undertaking translation study and every translator during translation practice. As the soul of translation, a translator needs to discover and settle down the common norms of source language in accordance with the cultures and conventions of the target language. In addition, he/she must pay attention to the relationship between the rights and interests in source language, and special norms settled for translation. Every translating strategy a translator chooses should satisfy both the universal norms and the personal ethics. With the embodiment of translators' subjectivity, translators must scrupulously abide by their professional ethics to build a bridge between the audiences and the world with their creation.

\section{Acknowledgement}

This research was supported by 2015 Key Research project of Education Science Planning of Hubei Province in China: The practical research of the 543 mode of the teachers' professional development based on Center for Research on Learning and Teaching (2015GA024).

\section{References}

[1] Baker, Mona and Saldanha, Gabriela. Routledge Encyclopedia of Translation Studies [Z]. London and New York: Routledge, 2009.

[2] Bassnett, Susan and Andre, Lefevere. (2001). Constructing Cultures: Essays on Literary Translation, [A] Shanghai: Shanghai Foreign Language Education Press.

[3] Bauman, Zygmunt. (1993). Postmodern Ethics. [M] Oxford UK and Cambridge USA: Blackwell Publishers.

[4] Lefevere, Andre. Translation, Rewriting and Manipulation of Literary Fame. [M] London and New York: Routledge Press, 1992.

[5] Steiner, George. After Babel[M]. London/Oxford: Oxford University Press. 